\title{
Determining the effects of black cumin seed oil on performance and meat fatty acid profile of broiler chickens
}

\author{
M. Demirci ${ }^{1 \#}$, M.A. Karslı \& Y. Aluç ${ }^{3}$ \\ ${ }^{1}$ Department of Laboratory and Veterinary Health, Vocational High School of Delice, University of Kırıkkale, Kırıkkale, \\ Turkey \\ ${ }^{2}$ Department of Animal Nutrition and Nutritional Disease, Faculty of Veterinary Medicine, University of Kırıkkale, \\ Kırıkkale, Turkey \\ ${ }^{3}$ Scientific and Technological Research Application and Research Center \\ University of Kırıkkale, Kırıkkale, Turkey
}

(Received 6 July 2019; Accepted 10 October 2019; First published online 28 October 2019)

Copyright resides with the authors in terms of the Creative Commons Attribution 4.0 South African License.
See: http://creativecommons.org/licenses/by/4.0/za
Condition of use: The user may copy, distribute, transmit and adapt the work, but must recognize the authors and the South African
Journal of Animal Science.

\begin{abstract}
This study was designed to investigate the effects of adding black cumin (Nigella sativa L.) seed (BCS) oil to diets for broiler chickens on their performance and the meat fatty acid profile of the meat. Broiler chicks were assigned to three groups. The unsupplemented control did not receive BCS oil. The two treated groups received $0.5 \%$ and $1 \%$ BCS oil. The live weight and live weight gain of the experimental groups were generally greater for the treated groups than for the control group. Feed consumption did not differ among groups, and thus the group that was fed the diet supplemented with $1 \%$ BCS oil was most efficient. Total saturated fatty acids were lower, and polyunsaturated fatty acids were greater in the treated groups, but monounsaturated fatty acids were greater in meat from the control group. As a result, it can be concluded that the addition of $0.5-1 \%$ BCS oil into the diets of broiler may improve the performance of chicks and enrich the meat quality by creating meaningful changes in meat fatty acid profiles, especially in terms of total polyunsaturated fatty acids.
\end{abstract}

Keywords: Ross broiler, fatty acids, nigella sativa, nutrition, yield

\#Corresponding author: m.demirci.kku@hotmail.com

\section{Introduction}

Black cumin (Nigella sativa L.) is a herbaceous annual plant that can grow to a height of $20-30 \mathrm{~cm}$. It is a well-known species, and its seeds and the oils obtained from them have been used worldwide as a spice for thousands of years. (The oil content ranges from 30\% to $45 \%$.) Also, it is known that its seeds enhance urine and milk production, make food more appetizing, and regulate menstruation, and its oils have topical effects against hair loss and dandruff in traditional phytotherapy (Baytop, 1999). In addition, Black cumin seed (BCS) and various active substances in its oil (such as thymoquinone) have anti-inflammatory, antipyretic, analgesic (Ali \& Blunden, 2003), antioxidant (Guler et al., 2007; Entok et al., 2014), antibacterial (Boka et al., 2014), anticoccidial (I Kadhim et al., 2018), immune responsiveness (Al-Mufarrej, 2013; Ali et al., 2014), and anticancer (Randhawa \& Alghamdi, 2011; Majdalawieh \& Fayyad, 2016) effects in modern medicine. Official institutions in some countries allow the use of and have granted patents on these products for the prevention of cancer, the development of the immune system, antiviral activities, and the treatment of diabetes, psoriasis, and asthma (Lim, 2013).

In the livestock sector, intensive studies are being conducted to discover natural products that may improve the performance of animals and the quality of their products. The addition of BCS to broiler diets has improved performance and carcass yields and various biochemical parameters, including serum cholesterol, triglyceride, and protein (Guler et al., 2006; Al-Beitawi \& El-Ghousein, 2008; Ali et al., 2014). In addition, BCS has improved intestinal morphology, increased egg yield, weight, and shell quality, and lowered the serum cholesterol in laying hens (Aydin et al., 2008; Boka et al., 2014).

Recent research on animal nutrition and animal food production has shown that studies on the production of healthier animal food for human consumption have gained attention and momentum. The logic 
on which these studies are based is to feed the animals with diets containing specific ingredients in an attempt to obtain animal products with the desired characteristics. Various studies have detailed the positive effects of BCS and its oil on animal and human health and the production of more healthful animal products for humans (Hassanien et al., 2015; Abd El-Hack et al., 2016; Kumar \& Patra, 2017). Most published experiments have utilized BCS in the diets, but few studies have been carried out with BCS oil. Thus, this study aimed to investigate the effects of BCS oil on the performance of broiler chickens and the fatty acid profile of the meat they produced.

\section{Materials and Methods}

The present study was carried out with 108 one-day-old broiler chicks (Ross 308) in a climatecontrolled environment, and over a 42-day period. All procedures were approved by Kırıkkale University Ethical Committee for Experimental Animals. Three groups were formed, consisting of 36 chicks each. Each group was divided into three replicates of 12 chicks. Three basal diets (starter, grower and finisher) were prepared. The diets for the control group were not supplemented. The treated groups received either $0.5 \%$ BCS or $1.0 \%$ BCS oil in addition to the diet that was fed to the control group. Diets were available ad libitum and the chicks were fed in groups.

Live weight (LW) and feed consumption (FC) were recorded at 14-day intervals, and live weight gain (LWG) and feed conversion rates were calculated for each period. The chemical contents of diets were determined by Weende analysis methods (AOAC, 2005). The feed ingredients and chemical composition of the diets that were used in the study are presented in Table 1.

Table 1 Ingredient composition and analysed content of the nutrients in the starter, grower and finisher diets fed to broiler chickens used in the trial (\% dry matter).

\begin{tabular}{|c|c|c|c|}
\hline \multirow[b]{2}{*}{ Feedstuffs } & \multicolumn{3}{|c|}{ Diets } \\
\hline & $\begin{array}{c}\text { Starter } \\
\text { (0-14 day) }\end{array}$ & $\begin{array}{c}\text { Grower } \\
\text { (15-24 day) }\end{array}$ & $\begin{array}{c}\text { Finisher } \\
(25-42 \text { day })\end{array}$ \\
\hline Corn & 34.4 & 37 & 38 \\
\hline Wheat & 15 & 15 & 15 \\
\hline Full-fat soy & 10 & 10 & 10 \\
\hline Soybean meal (44\%) & 33.5 & 28.7 & 27.7 \\
\hline Vegetable oil & 3.8 & 6 & 6 \\
\hline Limestone & 1 & 1 & 1 \\
\hline DCP & 1.5 & 1.5 & 1.5 \\
\hline Salt & 0.3 & 0.3 & 0.3 \\
\hline Vitamin and mineral premix ${ }^{1}$ & 0.25 & 0.25 & 0.25 \\
\hline DL-Methionine & 0.25 & 0.25 & 0.25 \\
\hline \multicolumn{4}{|c|}{ Chemical composition of feeds used during trial (\%) } \\
\hline Dry matter & 86.96 & 88.41 & 89.22 \\
\hline Crude protein & 23.54 & 22.22 & 21.18 \\
\hline Ether extract & 7.03 & 9.51 & 8.44 \\
\hline Crude fibre & 4.54 & 4.05 & 4.85 \\
\hline Crude ash & 5.19 & 5.44 & 5.01 \\
\hline Starch & 34.78 & 36.96 & 38.86 \\
\hline Sugar & 6.94 & 6.84 & 5.61 \\
\hline Metabolizable energy (MJ/kg) & 12.78 & 13.78 & 13.41 \\
\hline
\end{tabular}

\footnotetext{
${ }^{1}$ Vitamin-mineral premix composition of each $2.5 \mathrm{~kg}$ (2.5 kg was added to the $1000 \mathrm{~kg}$ diet): vitamin A: $1000000 \mathrm{IU}$; vitamin $\mathrm{D}_{3}$ : $3000000 \mathrm{IU}$; vitamin $\mathrm{E}: 20000 \mathrm{mg}$; vitamin $\mathrm{K}_{3}: 3000 \mathrm{mg}$; vitamin $\mathrm{B}_{1}: 3000 \mathrm{mg}$; vitamin $\mathrm{B}_{2}: 5000 \mathrm{mg}$; vitamin $B_{6}: 5000 \mathrm{mg}$; vitamin $B_{12}: 20 \mathrm{mg}$; vitamin $\mathrm{C}: 50000 \mathrm{mg}$; niacin: $25000 \mathrm{mg}$; pantothenic acid: $8000 \mathrm{mg}$; folic acid: $750 \mathrm{mg}$; biotin: $45 \mathrm{mg}$; choline chloride: $125000 \mathrm{mg}$; canthaxanthin: $2500 \mathrm{mg}$; carotenoic acid ester: $500 \mathrm{mg}$; manganese: 80000 mg; zinc: 60000 mg; iron: 60000 mg; copper: 5000 mg; iodine: 1000 mg; cobalt: 200 mg; selenium: $150 \mathrm{mg}$
} 
After 42 days on feed, nine chickens from each group (therefore from each replicate) were selected at random. The selected birds were slaughtered and breast meat samples (from Musculus pectoralis major and minor were taken from each to determine the fatty acid profiles. Lipid extractions were done using chloroform-methanol reagents (Folch et al., 1957). Fatty acid esters were obtained using boron trifluoride according to AOAC (2005) method 969.33. The fatty acid profiles were determined by gas chromatographymass spectrometry technology (Device: QP2010 Plus, Shimadzu, Japan; column: Agilent J \& W HP-88 GC, USA). The Supelco ${ }^{\circledR} 37$ Component FAME Mix CRM47885 reagent (Sigma-Aldrich, St. Louis, Missouri, USA) was used as the analytical standard. Fatty acid types were defined according to their retention times, and their concentrations were determined from the area under the chromatographic peaks.

The SPSS package program was used for the statistical analysis of the data obtained in the study (version 23.0, IBM Corp. Armonk, New York, USA). One-way ANOVA variance analysis and Duncan's multiple range test were used to determine the significance of differences between the experimental groups.

\section{Results and Discussion}

Weights attained by the broiler chickens at weekly intervals are shown in Table 2. Mean live weight of the day-old chicks at the initiation of the experiment was similar $(P>0.05)$. Subsequently, mean live weights of broilers supplemented with BCS oil were significantly greater at days 7,14 , and 42 than for the control group $(P<0.05)$. However, the differences in weight among the groups were not significant at days 21,28 , and $35(P>0.05)$. Overall, the broilers that were supplemented with $1.0 \%$ BCS oil gained $145.87 \mathrm{~g}$ more weight than those in the control group in this 42-day experiment $(P<0.05)($ Table 3$)$.

Table 2 Means $( \pm$ SE) for live weight $(\mathrm{g})$ of broilers supplemented with different levels of black cumin seed oil

\begin{tabular}{|c|c|c|c|c|}
\hline \multirow{2}{*}{ Age, day } & \multicolumn{3}{|c|}{ Treatment groups } & \multirow{2}{*}{$P$-value } \\
\hline & Control & $0.5 \%$ BCS oil & $1.0 \%$ BCS oil & \\
\hline 1 & $39.25 \pm 0.54$ & $39.58 \pm 0.55$ & $39.83 \pm 0.58$ & 0.758 \\
\hline 7 & $159.97^{B} \pm 3.31$ & $173.56^{\mathrm{A}} \pm 2.81$ & $177.56^{\mathrm{A}} \pm 2.60$ & 0.001 \\
\hline 14 & $424.03^{B} \pm 6.05$ & $445.74^{\mathrm{A}} \pm 7.31$ & $450.36^{A} \pm 6.38$ & 0.012 \\
\hline 21 & $868.00 \pm 11.77$ & $899.59 \pm 14.74$ & $897.94 \pm 12.51$ & 0.161 \\
\hline 28 & $1481.14 \pm 20.30$ & $1526.00 \pm 21.18$ & $1532.28 \pm 20.48$ & 0.166 \\
\hline 35 & $2175.66 \pm 25.40$ & $2272.03 \pm 36.87$ & $2267.28 \pm 31.72$ & 0.055 \\
\hline 42 & $2863.73^{B} \pm 33.17$ & $2977.71^{A} \pm 37.10$ & $3010.74^{A} \pm 25.59$ & 0.005 \\
\hline
\end{tabular}

${ }^{A, B}$ Row means with different superscripts differ significantly at $P<0.05$

BCS: Black cumin seed

Adding $0.2-0.5 \%$ BCS to the diets of broiler chicks has increased LWG (Shewita \& Taha, 2011; Ali et al., 2014). Further, increased LWG was reported for broilers fed BCS-supplemented diets at the rates of 11.5\% (Guler et al., 2006; Al-Beitawi \& El-Ghousein, 2008; Erener et al., 2010; Miraghaee et al., 2011). Rahman \& Kim (2016) observed similar effects with the addition of $1 \%$ and $2 \%$ BCS to diets fed to broilers. The addition of BCS from $2 \%$ to $4 \%$ also linearly increased LWG of broilers (Durrani et al., 2007). Al-Beitawi \& El-Ghousein (2008) and Massuodet al. (2014) reported a quadratic effect on LWG with the addition of BCS to diets of broiler chicks, suggesting there may be an optimal level for its use. Increasing the BCS level above $2 \%$ of diet DM resulted in a negative effect on LWG (Al-Beitawi \& El-Ghousein, 2008; Massuod et al., 2014),jvb and Shewita \& Taha (2011) observed that 0.6-1\% BCS may have a negative effect on LWG.

Saleh (2014) reported significant improvement in LW and LWG of chicks when they were fed $1 \mathrm{ml} / \mathrm{kg}$ DM of BCS oil compared with chicks in an unsupplemented control group. Similarly, when broilers were fed a diet that was supplemented with $0.10-0.15 \%$ BCS oil (Attia \& Al-Harthi, 2015) and when Japanese quail were a diet that was supplemented with $0.1 \%$ BCS oil (Tufan et al., 2015) the LWG of the birds was significantly increased. In the current study, both diets supplemented with BCS oil generally increased LW and LWG. Thus, it is possible to conclude that the addition of BCS oil to the diet at levels up to $1.0 \%$ increases the growth performance of broilers. Full-fat BCS may contain components that inhibit feed intake when BCS is added to diets at higher levels. These include alkaloids, saponins, volatile oils and other anti- 
nutritional factors (Guler et al., 2006). However, BCS oil increases the energy levels of diets, resulting in improved performance.

Although there were no statistically significant differences among the treatment groups in $\mathrm{FC}$, the feed conversion ratio (FCR) for broilers fed the diet containing 1.0\% BCS oil was significantly reduced compared with those in the $0.5 \%$ BCS oil and control groups $(P<0.05)$ when the whole experimental period was considered (Table 3). Similar to the results of the current study, the addition of BCS or BCS oil to broiler diets either had no effect or decreased the FC values (Durrani et al., 2007; Attia \& Al-Harthi, 2015). However, the addition of BCS oil to broiler diets significantly improved FCR (Erener et al., 2010; Saleh, 2014; Attia \& AlHarthi, 2015). The effect of supplementation with BCS oil on FCR apparently resulted from increased weight of the broilers.

Table 3 Means $( \pm$ SE) for live weight gain, feed consumption and feed conversion ratio for broilers supplemented with various levels of black cumin seed oil

\begin{tabular}{|c|c|c|c|c|c|}
\hline \multirow{2}{*}{ Trait $^{1}$} & \multirow[b]{2}{*}{ Age, days } & \multicolumn{3}{|c|}{ Treatment groups } & \multirow[b]{2}{*}{$P$-value } \\
\hline & & Control & $0.5 \%$ BCS oil & $1 \%$ BCS oil & \\
\hline \multirow{4}{*}{ LWG } & $0-14$ & $384.63^{B} \pm 5.56$ & $405.94^{A} \pm 6.95$ & $410.53^{A} \pm 5.92$ & 0.008 \\
\hline & $15-28$ & $1057.11 \pm 16.04$ & $1080.26 \pm 14.29$ & $1081.92 \pm 14.66$ & 0.429 \\
\hline & $29-42$ & $1360.13^{B} \pm 16.87$ & $1416.14^{\mathrm{A}} \pm 19.76$ & $1429.78^{A} \pm 15.75$ & 0.014 \\
\hline & $0-42$ & $2823.57^{\mathrm{B}} \pm 32.77$ & $2936.96^{\mathrm{A}} \pm 36.82$ & $2969.44^{\mathrm{A}} \pm 25.14$ & 0.004 \\
\hline \multirow{4}{*}{$\mathrm{FC}$} & $0-14$ & $564.43 \pm 8.67$ & $580.80 \pm 13.24$ & $589.72 \pm 9.09$ & 0.300 \\
\hline & $15-28$ & $1441.98 \pm 37.59$ & $1493.64 \pm 44.15$ & $1466.22 \pm 15.61$ & 0.601 \\
\hline & $29-42$ & $2273.63 \pm 10.22$ & $2358.00 \pm 70.74$ & $2210.11 \pm 7.44$ & 0.113 \\
\hline & $0-42$ & $4280.04 \pm 55.59$ & $4432.45 \pm 124.41$ & $4266.05 \pm 24.41$ & 0.332 \\
\hline \multirow{4}{*}{ FCR } & 0-14 & $1.48 \pm 0.02$ & $1.44 \pm 0.02$ & $1.45 \pm 0.02$ & 0.441 \\
\hline & $15-28$ & $1.37 \pm 0.02$ & $1.38 \pm 0.02$ & $1.36 \pm 0.02$ & 0.720 \\
\hline & $29-42$ & $1.68^{\mathrm{A}} \pm 0.02$ & $1.67^{A} \pm 0.02$ & $1.55^{B} \pm 0.02$ & 0.001 \\
\hline & $0-42$ & $1.52^{\mathrm{A}} \pm 0.02$ & $1.52^{\mathrm{A}} \pm 0.02$ & $1.44^{B} \pm 0.01$ & 0.001 \\
\hline
\end{tabular}

\footnotetext{
${ }^{A, B}$ Row means with different superscripts differ significantly at $P<0.05$

${ }^{1}$ LWG: live weight gain; FC: feed consumption; FCR: feed conversion ratio

BSC: Black cumin seed
}

The fatty acid profiles of the BCS oil and the diets used in the experiment are presented in Table 4. Vegetable oils generally contain more unsaturated fatty acids (UFAs) than saturated fatty acids (SFAs). According to the current data, BCS oil contains high amounts of oleic (C18:1) and linoleic $\left(C 18: 2_{n-6}\right)$ acids, constituting approximately $85 \%$ of the total fatty acids. The other major fatty acid components (about $13 \%$ ) were palmitic (C16:0) and stearic (C18:0) acids. Thus BCS oil is rich in unsaturated fatty acids, which is deemed desirable for healthy food production.

Nineteen fatty acids that were found in the breast meat of the samples and their proportions are presented in Table 5. Total saturated fatty acid content of the breast samples ranged from $31.35 \%$ to $34.04 \%$, whereas total UFA contents of the breast samples ranged from $65.96 \%$ to $68.65 \%$. Total SFA levels decreased significantly $(P<0.05)$ but total UFA levels increased significantly $(P<0.05)$ with addition of BCS oil to the broiler diets. Lower levels of saturated fat and trans fatty acids in the diet resulted in improved blood lipid profiles (Minihane \& Lovegrove, 2006). Many examples in the literature show that the fatty acid profiles of animal products (meat, eggs, etc.) can be manipulated with various oils and additives to the diet (Suksombat et al., 2006; Bostami et al., 2017; Kanakri et al., 2018; Skřivan et al., 2018). However, only a limited number of such studies used BCS and its oil. 
Table 4 Fatty acid profiles of black cumin seed oil and unsupplemented starter, grower and finisher diets fed to broilers in this trial (\% total fatty acid).

\begin{tabular}{lcccc}
\hline Fatty acids & $\begin{array}{c}\text { Black cumin } \\
\text { seed oil }\end{array}$ & Starter & Grower & Finisher \\
\hline C12:0, Lauric acid & - & 0.02 & 0.03 & 0.16 \\
C14:0, Myristic acid & 0.11 & 0.31 & 0.32 & 0.23 \\
C15:0, Pentadecanoic acid & 0.02 & 0.07 & 0.07 & 0.04 \\
C16:0, Palmitic acid & 9.38 & 16.24 & 16.60 & 15.18 \\
C16:1, Palmitoleic acid & 0.16 & 0.06 & 0.05 & 0.02 \\
C17:0, Heptadecanoic acid & - & 0.20 & 0.19 & 0.14 \\
C18:0, Stearic acid & 3.75 & 6.42 & 6.52 & 5.08 \\
C18:1, Oleic acid & 33.32 & 25.60 & 25.03 & 23.93 \\
C18:2(n-6), Linoleic acid & 51.97 & 45.33 & 45.48 & 49.11 \\
C18:3(n-3), a-Linolenic acid & 0.10 & 4.77 & 4.79 & 5.19 \\
C20:0, Arachidic acid & 0.24 & 0.32 & 0.31 & 0.31 \\
C20:1, Eicosenoic acid & 0.19 & 0.01 & 0.01 & 0.01 \\
C20:2(n-6), Eicosadienoic acid & 0.76 & 0.10 & 0.11 & 0.08 \\
C20:3(n-6), Eicosatrienoic acid & - & 0.26 & 0.27 & 0.28 \\
C20:4(n-6), Arachidonic acid & - & 0.11 & 0.02 & 0.06 \\
C20:5(n-3), Eicosapentaenoic acid & - & 0.09 & 0.10 & 0.07 \\
C22:6(n-3), Docosahexaenoic acid & - & 0.04 & 0.03 & 0.04 \\
C24:1, Nervonic acid & - & 0.03 & 0.06 & 0.04 \\
\hline
\end{tabular}

Saleh (2014) reported significant reductions in total SFA levels and increases in total monounsaturated fatty acid (MUFA) and polyunsaturated fatty acid (PUFA) levels of breast meat fatty acid profiles in chickens that were fed a diet supplemented with $1 \mathrm{ml} / \mathrm{kg}$ of BCS oil compared with the control group. Kumar et al. (2018) reported similar findings with the addition of BCS to the diet. The results of the current study support the findings of both Saleh (2014) and Kumar et al. (2018).

Palmitic (C16:0) and stearic (C18:0) acids were the major SFAs in breast samples, comprising more than $97 \%$ of total SFA in the breast. The remaining SFAs were lauric (C12:0), myristic (C14:0), pentadecanoic (C15:0), heptadecanoic (C17:0), and arachidic (C20:0) acids. Total PUFA levels ranged between 38.08 and $42.82 \%$ and total MUFA levels ranged from 25.83 to $27.88 \%$, among treatments. The addition of BCS oil to broiler diets significantly decreased $(P<0.05)$ total MUFA levels, but significantly increased total PUFA levels in the breast samples. The most dominant MUFA in all treatment groups was oleic (C18:1) acid, comprising over 90\% of total MUFA in breast samples. Among PUFAs, total $n-6 s$ ranged from $35.00 \%$ to $39.22 \%$, while total $n-3$ s were between 3.08 and $3.60 \%$. Both $n-6$ and n-3 levels increased with the addition of BCS oil to the broiler diets $(P<0.05)$. Arachidonic $\left(C 20: 4_{n-6}\right)$, EPA $\left(C 20: 5_{n-3}\right)$ and DHA $\left(\mathrm{C} 22: 6_{\mathrm{n}-3}\right)$ acids, which are considered among the most important PUFAs, were significantly greater in groups supplemented with BCS oil compared with control $(P<0.05)$. However, the $\mathrm{n}-6 / \mathrm{n}-3$ ratio was similar among treatment groups $(P>0.05)$, ranging from 10.94 to 11.91 .

PUFAs such as arachidonic, linoleic and linolenic acid are essential for many living organisms, including human beings. Polyunsaturated fatty acids are components of phospholipids, which are found in cell membranes and serve as precursors to the eicosanoids, which are a group of hormone-like inflammatory mediators (Minihane \& Lovegrove, 2006). PUFAs may also have significant beneficial cardiovascular effects (Ander et al., 2003). In addition to health benefits against cardiovascular diseases, n-3 PUFAs, namely EPA and DHA, have a variety of health benefits, including hypotriglyceridemic and anti-inflammatory effects. Studies have also indicated promising anti-ageing, anti-arthritis, anticancer, antidepression, antihypertensive, anti-inflammatory, antioxidant, and insulin-sensitizing effects of these fatty acids. Briefly, n-3 PUFAs seemed to have many health benefits that are mediated at least in part by their anti-inflammatory actions. Therefore, the consumption of these fatty acids from dietary sources needs to be encouraged (Siriwardhana et al., 2012). The addition of BCS oil to broiler diets increased the concentration of these fatty acids in the breast samples in the current study. Thus, consumption of such breast meat may improve the health of people. 
Table 5. Means ( \pm SE) for breast fatty acid profiles of broilers supplemented with different levels of Black cumin seed oil (\% total fatty acids)

\begin{tabular}{|c|c|c|c|c|}
\hline \multirow{2}{*}{ Fatty acids } & \multicolumn{3}{|c|}{ Treatment groups } & \multirow[b]{2}{*}{$P$-value } \\
\hline & Control & $0.5 \%$ BCS oil & 1.0\% BCS oil & \\
\hline $\mathrm{C} 12: 0$ & $0.04 \pm 0.01$ & $0.09 \pm 0.03$ & $0.07 \pm 0.01$ & 0.149 \\
\hline C14:0 & $0.26^{B} \pm 0.01$ & $0.34^{A} \pm 0.01$ & $0.35^{\mathrm{A}} \pm 0.01$ & 0.001 \\
\hline C15:0 & $0.06^{B} \pm 0.01$ & $0.10^{A} \pm 0.01$ & $0.11^{A} \pm 0.01$ & 0.001 \\
\hline C16:0 & $22.50^{\mathrm{A}} \pm 0.22$ & $19.60^{B} \pm 0.30$ & $20.42^{B} \pm 0.48$ & 0.001 \\
\hline C16:1 & $1.13 \pm 0.12$ & $0.93 \pm 0.07$ & $0.97 \pm 0.10$ & 0.325 \\
\hline C17:0 & $0.14^{B} \pm 0.01$ & $0.26^{A} \pm 0.01$ & $0.26^{A} \pm 0.01$ & 0.001 \\
\hline C18:0 & $10.99 \pm 0.14$ & $10.84 \pm 0.30$ & $11.17 \pm 0.54$ & 0.820 \\
\hline C18:1 & $25.98^{\mathrm{A}} \pm 0.37$ & $23.20^{B} \pm 0.38$ & $23.48^{B} \pm 0.88$ & 0.005 \\
\hline C18:2(n-6) & $31.22 \pm 0.32$ & $33.04 \pm 0.54$ & $32.05 \pm 0.97$ & 0.176 \\
\hline C18:3(n-6) & $0.11^{B} \pm 0.01$ & $0.18^{A} \pm 0.01$ & $0.17^{\mathrm{A}} \pm 0.01$ & 0.002 \\
\hline C18:3(n-3) & $2.64^{\mathrm{A}} \pm 0.14$ & $2.29^{A B} \pm 0.12$ & $2.06^{\mathrm{B}} \pm 0.16$ & 0.028 \\
\hline C20:0 & $0.05^{\mathrm{C}} \pm 0.01$ & $0.12^{A} \pm 0.01$ & $0.10^{B} \pm 0.01$ & 0.001 \\
\hline C20:1 & $0.13^{C} \pm 0.01$ & $0.22^{A} \pm 0.01$ & $0.18^{\mathrm{B}} \pm 0.01$ & 0.001 \\
\hline$C 20: 2_{(n-6)}$ & $0.35^{B} \pm 0.02$ & $0.69^{A} \pm 0.03$ & $0.69^{A} \pm 0.07$ & 0.001 \\
\hline$C 20: 3_{(n-6)}$ & $0.21^{B} \pm 0.01$ & $0.42^{\mathrm{A}} \pm 0.02$ & $0.40^{\mathrm{A}} \pm 0.03$ & 0.001 \\
\hline$C 20: 4_{(n-6)}$ & $3.11^{B} \pm 0.23$ & $4.88^{A} \pm 0.28$ & $4.92^{\mathrm{A}} \pm 0.66$ & 0.009 \\
\hline$C 20: 5_{(n-3)}$ & $0.06^{B} \pm 0.01$ & $0.17^{A} \pm 0.01$ & $0.16^{A} \pm 0.02$ & 0.001 \\
\hline$C 22: 6_{(n-3)}$ & $0.38^{B} \pm 0.03$ & $1.13^{\mathrm{A}} \pm 0.14$ & $1.01^{A} \pm 0.18$ & 0.001 \\
\hline C24:1 & $0.64^{B} \pm 0.03$ & $1.48^{\mathrm{A}} \pm 0.09$ & $1.46^{\mathrm{A}} \pm 0.19$ & 0.001 \\
\hline Total SFA ${ }^{1}$ & $34.04^{A} \pm 0.24$ & $31.35^{B} \pm 0.57$ & $32.48^{\mathrm{AB}} \pm 0.98$ & 0.030 \\
\hline Total MUFA ${ }^{2}$ & $27.88^{\mathrm{A}} \pm 0.34$ & $25.83^{B} \pm 0.43$ & $26.08^{B} \pm 0.80$ & 0.031 \\
\hline Total PUFA ${ }^{3}$ & $38.08^{C} \pm 0.27$ & $42.82^{A} \pm 0.35$ & $41.44^{B} \pm 0.34$ & 0.001 \\
\hline Total UFA & $65.96^{\mathrm{B}} \pm 0.24$ & $68.65^{\mathrm{A}} \pm 0.57$ & $67.52^{\mathrm{AB}} \pm 0.98$ & 0.030 \\
\hline SFA/UFA & $0.52^{A} \pm 0.01$ & $0.46^{B} \pm 0.01$ & $0.48^{\mathrm{AB}} \pm 0.02$ & 0.033 \\
\hline Total n-3 & $3.08^{B} \pm 0.11$ & $3.60^{A} \pm 0.09$ & $3.22^{B} \pm 0.07$ & 0.002 \\
\hline Total n-6 & $35.00^{C} \pm 0.31$ & $39.22^{A} \pm 0.28$ & $38.22^{B} \pm 0.35$ & 0.001 \\
\hline$n-6 / n-3$ & $11.54 \pm 0.55$ & $10.94 \pm 0.22$ & $11.91 \pm 0.27$ & 0.205 \\
\hline
\end{tabular}

\footnotetext{
${ }_{A, B, C}$ Row means with different superscripts differ significantly at $P<0.05$

${ }^{1}$ Saturated fatty acid (SFA): lauric (C12:0), myristic (C14:0), pentadecanoic (C15:0), palmitic (C16:0), heptadecanoic (C17:0), stearic (C18:0) and arachidic (C20:0) acids

${ }^{2}$ Monounsaturated fatty acid (MUFA): palmitoleic (C16:1), oleic (C18:1), eicosenoic (C20:1) and nervonic (C24:1) acids ${ }^{3}$ Polyunsaturated fatty acid (PUFA): linoleic (C18:2n-6), a-linolenic (C18:3n-3), $\gamma$-linolenic (C18:3n-6), eicosadienoic (C20:2n-6), eicosatrienoic (C20:3n-6), arachidonic (C20:4n-6), eicosapentaenoic (C20:5n-3) and docosahexaenoic (C22:6n-3) acids

BCS: Black cumin seed
}

Another important point that was observed in the results of this study was that supplementation with $0.5 \%$ BCS oil decreased the n-6/n-3 ratio numerically compared with the $1 \%$ BCS oil supplement, although this effect was not statistically significant. Because of the pathway competition between n-6 and n-3 PUFAs for enzyme activity, the ratio of n-6 to n-3 PUFA is important to human health (Ander et al., 2003). By increasing the n-3/n-6 PUFA ratio in the Western diet, the incidence of some chronic inflammatory diseases and obesity may be reduced (Patterson et al., 2012; Simopoulos, 2016). Although the ratio of n-6 to n-3 PUFAs in the typical Western diet is between 8: 1 and 25: 1 (Salem, 1999), recommendations from national health agencies are approximately 4: 1 (Holub, 2002). The n-6 to n-3 PUFA ratios observed here were not 
ideal, but were near the lower edge of the typical Western diet. In particular, the supplementation of broiler diets with $0.5 \%$ BCS oil appeared to have a positive effect on $n-3$ fatty acids.

\section{Conclusions}

The addition of BCS oil at levels up to $0.5 \%$ to the broiler diets created significant differences in live performance and breast fatty acid profiles of chickens. This type of manipulation in diets can lead to a reduction in total SFAs, and simultaneously enrich the body's total UFA and omega fatty acid levels and improve the meat quality of broiler chickens.

\section{Authors' Contributions}

MD designed the experiment, conducted the growth trial, collected the samples from the chicks and drafted the manuscript. MAK and YA analysed the samples and interpreted the results of the study. All authors approved the final version of the manuscript.

\section{Conflict of Interest Declaration}

There are no conflicts of interest.

\section{References}

Abd El-Hack, M.E., Alagawany, M., Farag, M., Tiwari, R., Karthik, K. \& Dhama, K., 2016. Nutritional, healthical and therapeutic efficacy of black cumin (Nigella sativa) in animals, poultry and humans. Int. J. Pharmacol. 12 (3), $232-$ 248. DOI: 10.3923/ijp.2016.232.248

Al-Beitawi, N. \&. El-Ghousein, S.S., 2008. Effect of feeding different levels of Nigella sativa seeds (black cumin) on performance, blood constituents and carcass characteristics of broiler chicks. Int. J. Poult. Sci. 7, 715-721. DOI: 10.3923/ijps.2008.715.721

Ali, B.H. \& Blunden, G., 2003. Pharmacological and toxicological properties of Nigella sativa. Phytother. Res. 17, 299305. DOI: 10.1002/ptr.1309

Ali, S., Mukhtar, M., Manzoor, S., Hssain, Z., Ali, A., Tabassum, R., Imran, M., Amer, M.Y. \& Bhatti, N., 2014. Effect of garlic, black seed and turmeric on the growth of broiler chicken. Pak. J. Nutr. 13, $204-210$. DOI: $10.3923 / p j n .2014 .204 .210$

Al-Mufarrej, S.I., 2013. Immune-responsiveness and performance of broiler chickens fed black cumin (Nigella sativa L.) powder. JSSAS. 13, 75-80. DOI: 10.1016/j.jssas.2013.01.006

Ander, B.P., Dupasquier, C.M., Prociuk, M.A. \& Pierce, G.N., 2003. Polyunsaturated fatty acids and their effects on cardiovascular disease. Exp. Clin. Cardiol. 8 (4), 164-172.

AOAC International, 2005. Official method of analysis. (18th ed.). Association of Analytical Chemists International, Maryland, USA.

Attia, Y.A. \& Al-Harthi, M.A., 2015. Nigella seed oil as an alternative to antibiotic growth promoters for broiler chickens. Europ. Poult. Sci. 79 (79), 1-12. DOI: 10.1399/eps.2015.80

Aydin, R., Karaman, M., Cicek, T. \& Yardibi, H., 2008. Black cumin (Nigella sativa L.) supplementation into the diet of the laying hen positively influences egg yield parameters, shell quality, and decreases egg cholesterol. Poult. Sci. 87, 2590-2595. DOI: 10.3382/ps.2008-00097

Baytop, T., 1999. Therapy with medicinal plants in Turkey (past and present). Nobel Tıp, Istanbul. (in Turkish)

Boka, J., Mahdavi, A.H., Samie, A.H. \& Jahanian, R., 2014. Effect of different levels of black cumin (Nigella sativa L.) on performance, intestinal Escherichia coli colonization and jejunal morphology in laying hens. J. Anim. Physiol. Anim. Nutr. 98 (2), 373-383. DOI: 10.1111/jpn.12109

Bostami, A.B.M.R., Seok Mun, H. \& Ju Yang, C., 2017. Breast and thigh meat chemical composition and fatty acid profile in broilers fed diet with dietary fat sources. J. Food Process Technol. 8, 672. DOI: 10.4172/2157-7110.1000672

Durrani, F.R., Chand, N., Zaka, K., Sultan, A., Khattak, F.M. \& Durrani, Z., 2007. Effect of different levels of feed added black seed (Nigella sativa L.) on the performance of broiler chicks. PJBS 10, 4164-4167. DOI: 10.3923/pjbs.2007.4164.4167

Entok, E., Ustuner, M.C., Ozbayer, C., Tekin, N., Akyuz, F., Yangi, B., Kurt, H., Degirmenci, I. \& Gunes, H.V., 2014. Antiinflammatuar and anti-oxidative effects of Nigella sativa L.: 18FDG-PET imaging of inflammation. Mol. Biol. Rep. 41, 2827-2834. DOI: 10.1007/s11033-014-3137-2

Erener, G., Altop, A., Ocak, N., Aksoy, H.M., Cankaya, S. \& Ozturk, E., 2010. Influence of black cumin seed (Nigella sativa I.) and seed extract on broilers performance and total coliform bacteria count. AJAVA. 5, 128-135. DOI: 10.3923/ajava.2010.128.135

Folch, J., Lees,M. \& Sloane Stanley, G.H., 1957. A simple method for the isolation and purification of total lipides from animal tissues. J. Biol. Chem., 226, 497-509.

Guler, T., Dalkılıç, B., Ertas, O.N. \& Çiftçi, M., 2006. The effect of dietary black cumin seeds (Nigella sativaL.) on the performance of broilers. Asian-Australas J. Anim. Sci., 19, 425-430. DOI: https://doi.org/10.5713/ajas.2006.425

Guler, T., Ertas, O.N., Kızıl, M., Dalkılıc, B. \& Ciftci, M., 2007. Effect of dietary supplemental black cumin seeds on antioxidant activity in broilers. Medycyna wet. 63, 1060-1063.

Hassanien, M.F.R., Assiri, A.M.A., Alzohairy, A.M. \& Oraby, H.F., 2015. Health-promoting value and food applications of black cumin essential oil: An overview. J. Food Sci. Technol. 52, 6136-6142. DOI: 10.1007/s13197-015-1785-4

Holub, B.J., 2002. Clinical nutrition: 4. Omega-3 fatty acids in cardiovascular care. CMAJ 166,608-615. 
I-Kadhim, L., Al-Zubaidi, M.T.S. \& Ah-Al-Saegh, M., 2018. Influence of dietary supplementation of Nigella sativa on experimental coccidiosis in broiler chickens. JEZS 6 (1), 652-656.

Kanakri, K., Carragher, J., Hughes, R., Muhlhausler, B. \& Gibson, R., 2018. The effect of different dietary fats on the fatty acid composition of several tissues in broiler chickens. Eur. J. Lipid Sci. Technol. 120 (1), 1700237. DOI: 10.1002/ejlt.201700237

Kumar, P. \& Patra, A.K., 2017. Beneficial uses of black cumin (Nigella sativa L.) seeds as a feed additive in poultry nutrition. World's Poultry Sci. J. 73, 872-885. DOI: https://doi.org/10.1017/S0043933917000848

Kumar, P., Patra, A.K., Mandal, G.P. \& Debnath, B.C., 2018. Carcass characteristics, chemical and fatty acid composition and oxidative stability of meat from broiler chickens fed black cumin (Nigella sativa) seeds. J. Anim. Physiol. Anim. Nutr. 102, 769-779. DOI: 10.1111/jpn.12880

Lim, T.K., 2013. Edible Medicinal and Non-Medicinal Plants: Volume 5, Fruits, Nigella Sativa, p. 554. Springer, Netherlands. DOI: 10.1007/978-94-007-5653-3

Majdalawieh, A.F. \& Fayyad, M.W., 2016. Recent advances on the anti-cancer properties of Nigella sativa, a widely used food additive. J. Ayurveda Integr. Med. 7 (3), 173-180. DOI: 10.1016/j.jaim.2016.07.004

Massuod, H.S.A., Mahfuds, L.D. \& Suprijatna, E., 2014. Effect of cage density and supplementation black cumin in the diet on blood status of broiler. Austr. J. Basic Appl. Sci. 8 (3), 354-359.

Minihane, A.M. \& Lovegrove, J.A., 2006. Health benefits of polyunsaturated fatty acids (PUFAs). In: Improving the fat content of foods. Woodhead Series in Food Science, Technology and Nutrition. pp. 107-140.

Miraghaee, S.S., Heidary, B., Almasi, H., Shabani, A., Elahi, M. \& Nia, M.H.M., 2011. The effects of Nigella sativa powder (black seed) and Echinacea purpurea (L.) Moench extract on performance, some blood biochemical and hematological parameters in broiler chickens. Afr. J. Biotechnol. 10 (82), 19249-19254. DOI: 10.5897/AJB11.2891

Patterson, E., Wall, R., Fitzgerald. G.F., Ross, R.P. \& Stanton, C., 2012. Health implications of high dietary omega-6 polyunsaturated fatty acids. J. Nutr. Metab. 2012:539426. DOI:10.1155/2012/539426

Rahman, M. \& Kim, S.J., 2016. Effects of dietary Nigella sativa seed supplementation on broiler productive performance, oxidative status and qualitative characteristics of thighs meat. Ital. J. Anim. Sci. 15, 241-247. DOI: 10.1080/1828051X.2016.1159925

Randhawa, M.A. \& Alghamdi, M.S., 2011. Anticancer activity of Nigella sativa (black seed) - a review. Am. J. Chin. Med. 39 (6), 1075-1091. DOI: 10.1142/S0192415X1100941X

Saleh, A.A., 2014. Nigella seed oil as alternative to avilamycin antibiotic in broiler chicken diets. S. Afr. J. Anim. Sci. 44 (3), 254-261. DOI: 10.4314/sajas.v44i3.7

Salem, N., 1999. Introduction to polyunsaturated fatty acids. Backgrounder 3 (1), 1-8.

Shewita, R.S. \& Taha, A.E., 2011. Effect of dietary supplementation of different levels of black seed (Nigella Sativa L.) on growth performance, immunological, hematological and carcass parameters of broiler chicks. WASET. 77, 788794.

Simopoulos, A.P., 2016. An increase in the omega-6/omega-3 fatty acid ratio increases the risk for obesity. Nutrients, 8 (3), 128. DOI:10.3390/nu8030128

Siriwardhana, N., Kalupahana, N.S. \& Moustaid-Moussa, N., 2012. Health benefits of n-3 polyunsaturated fatty acids: eicosapentaenoic acid and docosahexaenoic acid. Adv. Food Nutr. Res. 65, 211-222. DOI: 10.1016/B978-0-12416003-3.00013-5

Skřivan, M., Marounek, M., Englmaierová, M., Čermák, L., Vlčková, J. \& Skřivanová, E., 2018. Effect of dietary fat type on intestinal digestibility of fatty acids, fatty acid profiles of breast meat and abdominal fat, and mRNA expression of lipid-related genes in broiler chickens. PLoS One 13 (4), e0196035. DOI: 10.1371/journal.pone.0196035

Suksombat, W., Samitayotin, S. \& Lounglawan, P., 2006. Effects of conjugated linoleic acid supplementation in layer diet on fatty acid compositions of egg yolk and layer performances. Poult. Sci. 85 (9), 1603-1609. DOI: 10.1093/ps/85.9.1603

TSE, 1991. Animal feeds - Determination of metabolizable energy (chemical method TSE No 9610). Turkish Standards Institution, Ankara, Turkey.

Tufan, T., Arslan, C., Sarı, M. \& Kaplan, O., 2015. Effect of black cumin (Nigella sativa L.) seeds or black cumin oil addition to Japanese quail diets on growth performance, carcass traits and some blood parameters. Kafkas Univ. Vet. Fak. Derg., 21 (4), 593-599. DOI: 10.9775/kvfd.2015.12978 (in Turkish, English abstract) 